\title{
Family labor participation and child care decisions: the role of grannies
}

\section{Gema Zamarro ${ }^{1}$}

Received: 17 April 2019 / Accepted: 12 February 2020 / Published online: 28 February 2020

(c) The Author(s) 2020

\begin{abstract}
Grandparents, and in particular grandmothers, are an important source of informal child care for their grandchildren in most developed countries. The literature shows how these informal transfers of care can help promote female labor participation. However, less is known about how working-age grandmothers are combining care with their own labor participation. In this paper, I use data from the Survey of Health, Aging and Retirement in Europe and analyze to what extent child care is provided by grandmothers in ten European countries and how grandmothers are combining this task with paid work. I also revisit the question of whether the child care provided by grandmothers is encouraging the labor participation of their offspring. The empirical approach takes into account the simultaneity of labor market decisions and caregiving activities while controlling for grandmother's unobserved heterogeneity on their willingness to provide care to their grandchildren. I find a negative and significant effect of participating in the labor market on the probability of taking care of the grandchildren on a regular basis. I also find evidence that, for some countries, the child care provided by working-age grandmothers has a positive effect on the labor participation of their daughters.
\end{abstract}

Keywords Female labor participation $\cdot$ Child care decisions $\cdot$ Simultaneous estimation Panel data

JEL Classification $\mathrm{J} 13 \cdot \mathrm{J} 21 \cdot \mathrm{C} 30$

Special thanks to Arthur van Soest for all his comments. I would like to thank also seminar participants at the 61st Annual Scientific Meeting of the Gerontological Society of America, at Tilburg University and at The Netspar \& RTN meeting in Utrecht, especially to Katie Carman and Norma Coe, for useful comments. My thanks are also due to Maria Cristina Majo and Frederic Vermeulen for their help at the early stages of this work.

\footnotetext{
$凶$ Gema Zamarro

gzamarro@uark.edu

1 University of Arkansas, 219B Graduate Education Building, Fayetteville, AR 72701, USA
} 


\section{Introduction}

The increase in the proportion of working women is one of the most significant longterm trends observed during the past half-century in labor markets across OECD countries. However, even though female labor market participation has increased significantly across all OECD countries, not all countries show comparable levels. Ahn and Mira (2002) divided OECD countries into three groups. The first is the high participation group in which the female participation rate is higher than $60 \%$. This group includes the USA, Canada, UK, Sweden, and Norway. The second is the medium participation group with participation rates between 50 and $60 \%$ (Germany, France, Austria, and Portugal are in this group, among others) and the third is the low participation group with participation rates below 50\% (Italy, Spain, and Greece).

As a result of this dramatic rise in young women's labor force participation, the demand for non-maternal child care has increased significantly. As a consequence, different European countries have developed family-friendly policies to help improve access to affordable and quality child care. However, the nature and coverage of these policies differ significantly across countries. In particular, Southern European countries have a lower level of social protection. That is, they have lower social expenditures for families and children. This along with the characteristics of the local labor markets may have led families to provide the necessary services through informal channels, namely through grandmothers. ${ }^{1}$ Indeed, grandmothers have become one of the primary providers of child care for children in Europe.

On the other hand, since the mid-1980s labor force participation rates among middle-aged and older women have also been on the rise and governments across Europe have been increasing eligibility ages for retirement pensions stretching the working lives of their older citizens. Less attention, however, has been paid to the link between child care and labor force participation in older ages in the literature.

This paper will help answer the key question of how and to what extent child care is provided by working-age grandmothers and how this task is combined with paid work in ten European countries. I also revisit the question of whether this time transfer provided by grandmothers is encouraging the labor participation of their offspring. To do so, I use data from families drawn from the first wave of the Survey of Health, Aging and Retirement in Europe (SHARE), which includes grandmothers and their offspring with children. I also complement these data with information on different features of the formal child care systems across European countries (i.e., generosity of parental leaves, fees for child care) and study their effect on the provision of care and on mothers' labor participation.

The empirical approach takes into account the simultaneity of labor market decisions and caregiving activities while controlling for grandmother's unobserved heterogeneity on their willingness to provide care to their grandchildren. Here I exploit

\footnotetext{
${ }^{1}$ In this paper, I focus only on grandmothers and do not study grandfathers. In my data sample around $14 \%$ of grandmothers declare providing grandchild care once per day whereas only $9 \%$ of grandfathers do so. The share of grandparents taking care of grandchildren in a weekly basis is more comparable across gender. However, previous literature has found that male labor participation does not significantly adjust in response to grandparenthood (see e.g., Rupert and Zanella 2018 or Backhaus and Barslund 2019). Hence my focus on grandmothers.
} 
the fact that I have information about multiple offspring with children for most grandmothers. In line with recent work that used eligibility ages for retirement as external instruments for grandmothers' labor participation (see Aparicio Fenoll and VidalFernandez 2015; Aparicio Fenoll 2018; Battistin et al. 2015; Bratti et al. 2018), I use the information on eligibility for early retirement as an exclusion restriction to aid identification of the empirical model. I find a negative and significant effect of participating in the labor market on the probability of working-age grandmothers of taking care of their grandchildren on a regular basis. I also find evidence that, for some countries, the child care provided by grandmothers has a positive effect on the labor participation of their daughters.

The rest of the paper is organized as follows. Section 2 reviews the economic literature on child care and mothers' labor participation. Section 3 gives and overview of child care systems across European countries, and Sect. 4 presents the dataset and the variables that I use in the empirical analysis. Section 5 discusses the econometric methodology. Section 6 presents the empirical results. Finally, Sect. 7 contains the conclusions.

\section{Previous literature}

Most of the early literature focused its attention on studying the effect of formal child care costs on female labor supply. Heckman (1974), Blau and Robins (1988), Connelly (1992), Ribar (1992) and Kimmel (1998), among others, studied the relationship between formal child care costs and female labor market participation in the USA and the UK. Using different methodologies, these studies arrived at the conclusion that female labor participation is significantly influenced by child care policies. In contrast, for the case of Europe, Wroolich $(2004,2011)$ studied the effect of child care costs on the participation decision of mothers in Germany and found negative but very small effects. A possible explanation for this different result is the fact that, in Germany, subsidized child care is rationed and private child care is only available at a relatively much higher cost. In fact, Kornstad and Thoresen (2007) and Gustafsson and Stafford (1992) studied the case of Norway and Sweden, respectively, and found similar effects. They found significant effects of child care costs on female labor participation but only in those areas of the country that did not have a problem of rationed child care supply. del Boca and Vuri (2005) also found similar results for the case of Italy. Overall these papers showed how female labor participation is affected by the availability and cost of formal child care. All of these early papers, however, focused on the provision of formal child care and ignored the possibility of informal care providers.

There is a growing recent literature studying the role of informal care provided by grandmothers on their daughter's labor supply. In one of the earlier studies in the topic, Cardia and $\mathrm{Ng}$ (2003) calibrated an overlapping generation model extended to allow for both time and money transfers using data from the USA. They found that intergenerational time transfers in the form of grandparenting have important positive effects on labor supply and capital accumulation. Similarly, Dimova and Wolff (2011) presented a theoretical framework to analyze the effect of grandparents' time and money transfers on maternal labor supply. Using data for Europe from the SHARE study, they 
found a strong positive association between the provision of frequent grandchild care (i.e., on a daily or weekly basis) and daughters' labor force participation. Similarly, Garcia-Moran and Kuehn (2017) used data from the German socioeconomic panel (SOEP) and simulated a model to study how daughters' labor participation would change with the availability of grandparent-provided child care. They found that an increase in the availability of grandparental care would increase daughters' fertility and labor participation but at the cost of reduced geographical mobility. Posadas and Vidal-Fernandez (2013) found similar results using American data from the National Longitudinal Survey of Youth 1979. Using the death of the maternal grandmother as a natural experiment that reduces the availability of grandparents' provided child care, they found a significant positive effect of grandparental care on female labor participation.

Some other recent papers have aimed to estimate the causal effect of grandmothers' provided child care on daughters' labor force participation exploiting changes in retirement pensions eligibility ages as a result of recent pensions reforms in Italy. Aparicio Fenoll and Vidal-Fernandez (2015) found that as grandmothers are induced to participate longer in the labor market, they provide less grandchild care to their daughters and, as a result, their daughters decrease labor force participation. Similarly, Battistin et al. (2015), using also data from Italy, found that delayed retirement due to pension reforms led to a reduction in the probability of mothers participating in the labor market but only for later ages. Similarly, Bratti et al. (2018) found a positive and significant effect on the labor supply of mothers if they have a grandmother that became eligible for retirement pensions. Finally, Aparicio Fenoll (2018) uses data from SHARE and differential pension eligibility retirement ages across countries to study whether the effect of grandmothers' retirement on daughters' labor participation varies by country depending on its family policies. She finds that the effect of grandmaternal retirement on daughters' labor participation is highest and positive only in those countries with low family benefits.

Although grandmaternal provided child care appears to benefit the labor force participation of daughters, this informal child care could come at a cost. This is so because most grandparents are in their working age and thus should reconcile their own jobs with the provision of grandchild care. However, less is known in the literature about how grandmothers are combining care with their own labor participation. The main challenge here is to find ways to estimate causal effects given the simultaneous nature of grandmothers' provided child care and their own labor force participation decisions.

Early studies were only able to provide correlations between grandparental child care and labor participation. Lei (2008) using data from the Health and Retirement Study (HRS) investigated the determinants of transfers to children and paid employment of older women. The study estimated reduced-form models for money and time transfers provided by grandmothers, as well as for their labor force participation, separately. As such, this study did not provide estimates of the causal effect of grandparents' labor force participation on the provision of grandchild care. The main finding in Lei (2008) is that American women who have a new grandchild are more likely to provide more money and time transfers to their children while they do not appear to change their time in paid employment. In contrast, Ho (2015) used the same data 
source and found significant correlations between having an additional grandchild and grandparents' labor supply, both in terms of labor participation and the number of hours worked, but of varying signs depending on grandparental characteristics. Similarly, Lumsdaine and Vermeer (2015) found that the arrival of a new grandchild was associated with an increase in the probability of grandmothers' retirement among those close to retirement age. Finally, Reinkowski (2013) found a negative association between grandmaternal care and employment among older women in Europe.

More recent studies have aimed to estimate the causal effect of grandparenting on labor participation. Rupert and Zanella (2018), using panel data from the Panel Study of Income Dynamics in the USA. and an instrumental variable approach based on the differential in time at which the parents of boys and girls become grandparents, found no significant effect of grandparenting on employment but a negative effect on employed grandmothers' hours of work as they become a grandmother, especially for those grandmothers with less attachment with the labor market (e.g., working parttime). In contrast, Frimmel et al. (2017) used data from Austria and found that having a first grandchild increases the probability of leaving the labor market. Similarly, Backhaus and Barslund (2019) used data from SHARE for nine European countries. Following the same identification strategy as in Rupert and Zanella (2018), they found a negative impact of grandparenthood on the labor force participation of working-age women (aged 55-64).

My paper contributes to this growing literature. I use data from the first wave of the Survey of Health, Aging and Retirement in Europe (SHARE) and analyze to what extent child care is provided by grandmothers in ten European countries and how grandmothers are combining this task with paid work. I also revisit the question of whether the child care provided by grandmothers is encouraging the labor participation of their offspring. In contrast with the recent literature that estimates the causal effect of new grandparenting on labor supply, I focus my analysis on current workingage grandmothers. I then aim to arrive at the causal effect of grandmother's labor force participation in the provision of care by estimating the grandmother's care and labor participation decisions jointly, controlling for grandmother's unobserved heterogeneity, and using early retirement eligibility ages as external instruments for the grandmother's labor participation decision. In this respect, this paper's identification strategy goes in line with that of Aparicio Fenoll and Vidal-Fernandez (2015), Battistin et al. (2015), Batti et al. (2018) and Aparicio Fenoll (2018) described above. However, the main difference in this paper is that the analysis considers only working-age grandmothers and the estimated effects are those of changing labor force participation on provided grandchild care induced by early retirement eligibility.

\section{Institutional support for child care across Europe}

Parents throughout Europe share the common challenge of balancing labor in paid work and child care. Yet despite relatively common problems, social and labor market policies vary dramatically across countries in the level of support that they provide to parents. The first column of Table 1 shows public social expenditures in family policies for several European countries during the timeframe of our analytical sample. The 
Table 1 Public social expenditure in family policies and proportion of children (aged under 3 ) in formal care. Source: OECD (2004) Social Expenditure Database and OECD (2001)

\begin{tabular}{llc}
\hline Country & Soc. Expen. (\% of GDP 2001) & \% Child. in F. care \\
\hline Austria & 2.9 & 4 \\
Belgium & 2.3 & 30 \\
Denmark & 3.8 & 64 \\
France & 2.8 & 29 \\
Germany & 1.9 & 10 \\
Greece & 1.8 & 3 \\
Italy & 1.0 & 6 \\
Netherlands & 1.1 & 6 \\
Spain & 0.5 & 5 \\
Sweden & 2.9 & 48 \\
\hline
\end{tabular}

Nordic Governments (Denmark and Sweden) are the most generous ones, employing a range of policies designed to help their citizens balance their work and family life. In these countries, public daycare is heavily subsidized and it is common to have flexible work schedules. In contrast, in central European countries (Austria, Netherlands, Switzerland, Germany, and France) child care providers are mainly private institutions although facilities are often subsidized by the Government. A big challenge in some of these countries appears to be a lack of available child care slots (see e.g., Wrohlich 2004). Finally, in southern Europe (Italy, Spain, and Greece), like in central Europe, child care providers are mostly private institutions but Government subsidies are limited in this case. The higher generosity of Northern European countries is correlated with a higher proportion of children (aged under 3 ) using formal care facilities, as can be seen in the second column of Table 1 .

Within each country, at least three areas of family policy influence dominant patterns of parental caregiving. First, family leave policies grant parents the right to take time off for caregiving, especially for younger children. These policies replace some or all wages during parents' time off. Across Europe, there are different types of childrelated leave, which generally offer employment protection during absence from work to care for children. The most common forms of child-related leaves are: maternity leave (or pregnancy leave) offering a leave of absence for employed women at around the time of childbirth, paternity leave offering leave of absence for employed fathers at the time of childbirth, and parental leave which offers an employment protected leave of absence for employed parents, normally supplementary to specific maternity and paternity leave periods and usually following the period of maternity leave.

Comparing the generosity of child leave policies across countries is not an easy task given the cross-country differences in the duration of leaves and levels of payment. Plantenga and Siegel (2004) in an attempt to compare parental leave policies across countries constructed an "effective leave" measure computed by weighting the duration of the legislated parental leave by the level of the offered replacement wage or benefit. The first column of Table 2 shows the "effective leave" duration for the European 
Table 2 Family leave policies, cost of child care and labor market characteristics

\begin{tabular}{llll}
\hline Country & $\begin{array}{l}\text { Effective parental } \\
\text { leave (weeks) }\end{array}$ & $\begin{array}{l}\text { Fees charged by child } \\
\text { care centers }(\% \text { of } \\
\text { average wage) }\end{array}$ & $\begin{array}{l}\text { Incidence of part-time } \\
\text { employment } \\
\text { female employment })^{\mathrm{c}}\end{array}$ \\
\hline Austria & 71 & 10 & 29.3 \\
Belgium & 18 & 20 & 33.3 \\
Denmark & 36 & 8 & 23.8 \\
France & 48 & 25 & 23.1 \\
Germany & 64 & 9 & 37 \\
Greece & 12 & 4 & 10.5 \\
Italy & 24 & N.A & 28.7 \\
Netherlands & 11 & 17 & 60.2 \\
Spain & 48 & 30 & 16.9 \\
Sweden & 119 & 5 & 20.8 \\
\hline
\end{tabular}

NA not available

${ }^{a}$ Source: Plantenga and Siegel (2004)

${ }^{\mathrm{b}}$ Refers to a full-time fee for a 2 years old. Source: OECD (2007)

${ }^{\mathrm{c}}$ Source: OECD (2020). Data refers to 2004

countries in our analytical sample as calculated by Plantenga and Siegel (2004). The longest parental leave is in Sweden (119 weeks), followed by Austria (71 weeks), Germany (64 weeks) and Denmark (36 weeks). The shortest parental leaves are offered in The Netherlands (11 weeks), Greece (12 weeks) and Italy (24 weeks).

Secondly, different working schedules help parents to free up care giving time. Flexible labor arrangements with the possibility of part-time employment may help families combine work and child responsibilities. The third column of Table 2 presents the incidence of total part-time employment as a percentage of total female employment for the European countries considered in this paper. The incidence of part-time employment varies considerably across European countries ranging from around $60 \%$ in the Netherlands to only $10.5 \%$ percent in Greece. The highest incidence of parttime employment takes place in The Netherlands, Germany, and Belgium. On the other hand, Greece and Spain are in the group of countries with the lowest part-time employment rates.

Finally, public provisions for early childhood education and care also vary substantially across European countries. The second column of Table 2 shows OECD (2007) estimates of the "typical" fees charged by accredited child care centers, for children aged 2, as a percentage of the average wage in the country. Fees charged by child care centers range from $4 \%$ in Greece to $30 \%$ in Spain. In addition, compulsory school ages also vary from 3 to 6 years old among European countries. Moreover, some European countries offer public preschool education with enrollment ages ranging from 2 years old in France to 6 years old in Sweden. Eligibility for public preschool education is universal for almost all European countries and in most countries, it is available free of charge, although in some countries like The Netherlands and Germany are only partly subsidized. Another important related feature is the opening hours offered in these 
Table 3 Early childhood education systems

\begin{tabular}{llll}
\hline Country & $\begin{array}{l}\text { Starting age of compul- } \\
\text { sory education }\end{array}$ & $\begin{array}{l}\text { Starting age of preschool } \\
\text { in public school centers b }\end{array}$ & $\begin{array}{l}\text { Opening hours for preschool } \\
\text { public education }\end{array}$ \\
\hline Austria & 6 & 4 & Part-time \\
Belgium & 6 & 2.5 & Part-time \\
Denmark & 7 & 5 & Full-time \\
France & 6 & 2 & Part-time \\
Germany & 6 & 3 & Part-time \\
Greece & 6 & 3.5 & N.A \\
Italy & 6 & 3 & Varies \\
Netherlands & 5 & 4 & Part-time \\
Spain & 6 & 3 & Full-time \\
Sweden & 7 & 6 & Full-time \\
\hline
\end{tabular}

N.A not available

a Source: Eurydice at Nfer: www.nfer.ac.uk/eurydice

b,c Source: OECD (2001) and The clearinghouse for international developments in child, youth and Family policies at Columbia University. A full-time place is defined as a minimum of 30 weekly hours

public preschool centers. Most of the European countries considered have opening hours of less than 30 weekly hours. Table 3 summarizes the relevant characteristics of preschool education and the age of compulsory education for different European countries.

The characteristics of the child care system along with the characteristics of the labor market may have led families to seek the necessary social services through the informal market, i.e., through grandmothers. Figure 1 shows the proportion of grandmothers who report taking care of their grandchildren at least once per week in our data. On average, working-age grandmothers take care of their grandchildren with a higher probability than older grandmothers. Overall, about $35 \%$ of grandmothers aged 50-65 report taking care of their grandchildren at least once per week. $24 \%$ of these grandmothers report taking care of their grandchildren in a weekly basis as compared with $12 \%$ who report taking care of them daily. Greek grandmothers appear to be the ones who take care of their grandchildren in the highest proportion, followed by Italy, Spain and The Netherlands. As illustrated in Fig. 2, these countries also have the lowest proportion of grandmothers in paid employment.

\section{Data}

In this paper, I use data from the first wave of the Survey of Health, Aging and Retirement in Europe (SHARE) Release2 2004 (Börsch-Supan 2018). SHARE is a multidisciplinary, cross-national, individual-level database containing detailed information on health, socioeconomic status, social and family networks. The uniqueness of SHARE lies on three important and appealing features of the data: multidisciplinarity, longitudinal character, and cross-country comparability. The first wave of SHARE 


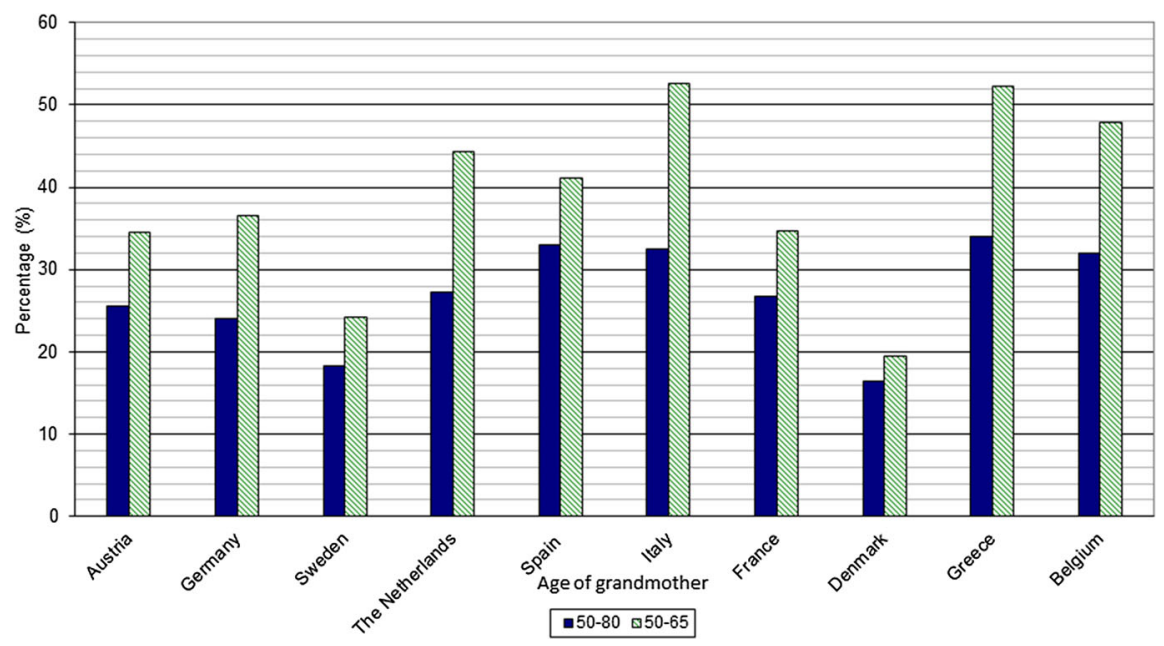

Fig. 1 Percentage of grandmothers who take care of their grandchildren (weekly). Source: SHARE 2004

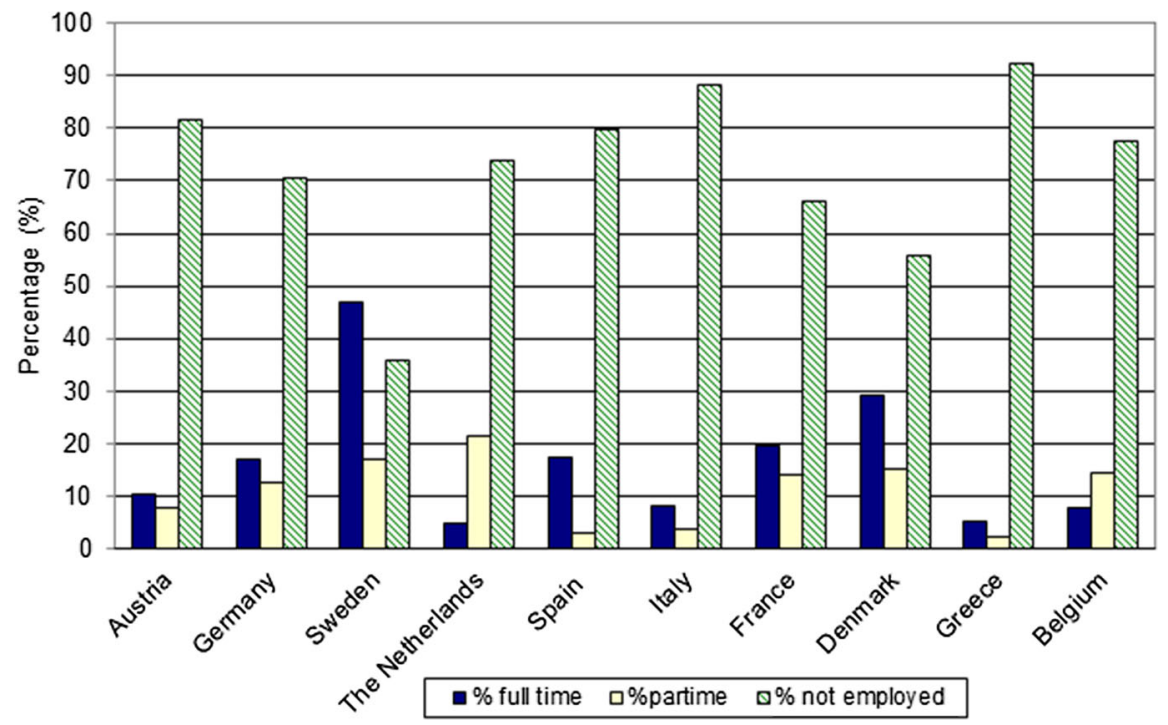

Fig. 2 Current job situation for women 50-65 who have grandchildren. Source: SHARE 2004

contains information of about 28,000 continental Europeans who are over the age of 50. Countries included in Release 2 of the first wave of this survey (2004) are Sweden, Denmark, Germany, The Netherlands, France, Austria, Italy, Spain, Greece, and Belgium. ${ }^{2}$ The cross-national nature of SHARE data is ideal for learning from different family-related policies across Europe. SHARE offers, for the first time, comparable data across diverse European countries including health information, socioeconomic

2 SHARE also includes Israel and Switzerland. I excluded Israel since it was added after 2004, and Switzerland due to its low response rate and extremely small sample size. 
Table 4 Distribution of observations by number of children. Source: SHARE 2004 release2

\begin{tabular}{lrl}
\hline Number of children & Freq. & Percent \\
\hline 1 & 1001 & 39.33 \\
2 & 1072 & 42.12 \\
3 & 408 & 16.03 \\
4 & 64 & 2.51 \\
Total & 2545 & 100 \\
\hline
\end{tabular}

variables (labor situation, wealth, consumption, housing, etc.), as well as information related to social support. SHARE's structure gives the possibility of analyzing a wide variety of questions related to population aging and the quality of life of the elderly. This paper uses information about the labor status of grandmothers, their offspring, number of grandchildren, and child care time allocated to taking care of grandchildren, as well as other sociodemographic information relevant for the analysis.

The analytical sample consists of working-age grandmothers (i.e., those between 50 and 65 years old) with complete data records. SHARE provides information about the number of living children and some basic information about them (gender, age and residence closeness). In addition, more detailed information is asked about up to four children. When the grandmother had more than four children, the information is asked about those four children who currently live closer and who are older. This will imply that my estimates could be interpreted as an upper bound estimate of the possible effect as these are the children with potentially the highest needs of care. I selected those sons or daughters who have children younger than 13 years old to be included in the analytical sample of parents and corresponding grandmothers. The final sample consists of 1689 unique grandmothers who contributed to 2545 child-grandmother observations. Table 4 shows the distribution of observations by the number of children. Most grandmothers have two children who are parents of grandchildren younger than 13 (about $42 \%$ of the sample) and so, contribute two observations to the dataset. This is followed by grandmothers with one or three children (about 39\% and 16\% of the sample). Finally, about $2 \%$ of the sample of grandmothers report having four children. As it is described in the next section, our empirical approach will exploit the fact that we observe grandmothers providing care to multiple grandchildren to control for grandmothers' specific unobserved heterogeneity, i.e., their unobserved willingness to take care of all of her grandchildren.

Tables 5 and 6 show descriptive statistics for grandmothers and their offspring, respectively. The average age of grandmothers in the analytical sample is about 58 and a majority, about $73 \%$, are currently married. Only about $17 \%$ of these grandmothers report having an education at the high level of college and $31 \%$ reports participating currently in the labor market. About $32 \%$ of grandmothers in the sample report not being in good health. Concerning the offspring, their average age is about 34 years old and a majority of daughters and sons are currently working (71\% and 96\%, respectively). On average, they have about two children and $46 \%$ of daughters and about $33 \%$ of sons appear to receive regular care for their children provided by their grandmothers. The average age of the youngest child is about four years old. Most offspring, 
Table 5 Descriptive statistics grandmothers. Source: SHARE 2004 release2

\begin{tabular}{lrll}
\hline Variable & Mean & Variable & Mean \\
\hline Labor participation (\%) & 31.32 & Other household income (millions of Euros) & 0.0052 \\
Age & 58.54 & Austria (\%) & 5.98 \\
High education level (\%) & 16.70 & Germany (\%) & 9.59 \\
Medium education level (\%) & 30.91 & Sweden (\%) & 14.98 \\
Married (\%) & 72.82 & Netherlands (\%) & 13.91 \\
Less than good health (\%) & 32.15 & Spain (\%) & 6.22 \\
2+ chronic conditions (\%) & 39.85 & Italy (\%) & 7.93 \\
Limited mobility (\%) & 49.32 & France (\%) & 11.78 \\
Maximum grip (kg/100) & 0.29 & Denmark (\%) & 8.58 \\
Partner L. participation (\%) & 16.04 & Greece (\%) & 6.10 \\
High educated partner (\%) & 9.35 & Belgium (\%) & 14.92 \\
Medium educated partner (\%) & 14.62 & N. obs & 1689 \\
\hline
\end{tabular}

Table 6 Descriptive statistics offspring. Source: SHARE 2004 release 2

\begin{tabular}{lll}
\hline Variable & $\begin{array}{l}\text { Daughter } \\
\text { Mean }\end{array}$ & $\begin{array}{l}\text { Son } \\
\text { Mean }\end{array}$ \\
\hline Care received (\%) & 46.14 & 33.58 \\
Labor participation (\%) & 71.28 & 96.07 \\
Age & 33.74 & 34.82 \\
High education (\%) & 25.62 & 26.03 \\
Medium education (\%) & 56.40 & 54.62 \\
N. of children & 1.86 & 1.82 \\
Age of youngest child & 4.40 & 3.97 \\
Married (\%) & 82.71 & 83.07 \\
Living further than $25 \mathrm{~km}(\%)$ & 24.38 & 24.89 \\
N. obs & 1452 & 1093
\end{tabular}

about $83 \%$, are currently married, and only about $24 \%$ live further than $25 \mathrm{~km}$ from their mothers.

\section{Econometric model}

The empirical approach in this paper takes into account the relationship between labor market decisions, caregiving activities, and the fact that these decisions are made in a family context. In particular, the analysis is based on the following reduced-form model of the labor market participation and caregiving decisions:

$$
\begin{aligned}
P D_{j}^{*} & =\alpha_{D} C_{j}+\beta_{D} X_{D j}+\gamma_{D}^{c} I_{j c}-\varepsilon_{D j} \\
\mathrm{PGM}_{i}^{*} & =\beta_{\mathrm{GM}} X_{G M i}+\gamma_{G}^{c} I_{i c}^{P}-\varepsilon_{G M i}
\end{aligned}
$$




$$
C_{i j}^{*}=\alpha_{i}+\alpha_{\mathrm{GM}} \mathrm{PGM}_{i}+\gamma Z_{i j}+\gamma_{\mathrm{GM}}^{c} I_{j c}-\varepsilon_{C i j}
$$

$P D_{j}^{*}$ is the net utility for the offspring $(j)$ to participate in the labor market, $\mathrm{PGM}_{i}^{*}$ is the net utility of the grandmother $(i)$ to participate in the labor market and, $C_{i j}^{*}$ is the net utility for the grandmother $(i)$ to take care of the children of her offspring $(j)$ on a regular basis (at least once per week). In the same way, $C_{j}$ is a dummy variable that takes the value one if the grandmother takes care of the children of her offspring $(j)$ on a regular basis. $\mathrm{PGM}_{i}$ is another dummy variable that takes the value one if grandmother (i) participates in the labor market (full-time or part-time). $X_{D j}$ are observed variables that affect the offspring's utility of participating in the labor market. These variables include: age, level of education, number of children, and marital status. $X_{G M i}$ are observed variables that affect the grandmother's utility of participating in the labor market. These variables include age, level of education, health status, marital status, labor status and level of education of the partner, other household income, and country controls. Finally, $Z_{i j}$ includes all the observed variables that may affect the decision of taking care of grandchildren such as age and number of grandchildren, grandmother's health status, distance to the children's home, a dummy for the offspring being a daughter and offspring's marital status.

$I_{j c}$ denotes a set of institutional variables affecting the grandmother's care and offspring's labor participation decisions. In particular, I use variables with information about each country's parental leave policies and child care fees interacted with a dummy indicating whether the youngest grandchild is younger than the starting age of preschool in public school centers set in their country. Similarly, $I_{j c}$ also includes information on whether the youngest grandchild in the family is in between the starting age of public preschool education and/ or above the starting age of compulsory education, interacted with country dummies, with the aim to capture country differences in preschool and compulsory education systems (e.g., different flexibility in opening hours). Finally, country fixed effects are also included directly to capture any remaining institutional differences across countries.

Importantly, $I_{i c}^{P}$ includes institutional information about eligibility to public pension systems which affect grandmothers' labor participation decisions. Specifically, I introduce a dummy variable indicating whether the grandmother is above the statutory early retirement age set in her country. ${ }^{3}$ This is an important variable that acts as an external instrument and aids identification of the model as it is described below.

$\alpha_{i}$ represents the grandmother's specific unobserved heterogeneity. That is, the grandmother's "taste" or willingness to take care of any of her grandchildren. $\varepsilon_{D j}$, $\varepsilon_{G M i}$ and $\varepsilon_{C i j}$ contain any remaining unobservables. Note that, with respect to the participation decisions of the offspring, our data contain observations of sons and daughters belonging to the same family. As a result, the error terms $\left(\varepsilon_{D j}\right)$ are most probably correlated among offspring. This is taken into account in the model by obtaining cluster-robust standard errors.

Under this model's assumptions, thus, the observed decisions of the offspring's labor participation and grandmothers' labor participation and caregiving decisions

\footnotetext{
3 The main source for this data was Natali (2004) but the data were supplemented with information from OECD (2003), The Bartelsmann Foundation (2003), Sundén (2004), Preesman (2006), and OECD (2005).
} 
will follow this specification:

$$
\begin{aligned}
P D_{j} & =1\left(\alpha_{D} C_{j}+\beta_{D} X_{D j}+\gamma_{D}^{c} I_{j c}-\varepsilon_{D j}>0\right) \\
\mathrm{PGM}_{i} & =1\left(\beta_{\mathrm{GM}} X_{G M i}+\gamma_{G}^{c} I_{i c}^{P}-\varepsilon_{G M i}>0\right) \\
C_{i j} & =1\left(\alpha_{i}+\alpha_{\mathrm{GM}} \mathrm{PGM}_{i}+\gamma Z_{i j}+\gamma_{\mathrm{GM}}^{c} I_{j c}-\varepsilon_{C i j}>0\right)
\end{aligned}
$$

where $1(A)$ is an indicator function that takes value 1 if the event $A$ is true. Estimates of the parameters of interest can be obtained considering distributional assumptions for the unobservables and maximizing the corresponding likelihood function. It is natural to think that the unobservable determinants of the participation decision of the grandmother $\left(\varepsilon_{G M i}\right)$ and those of the care decision $\left(\alpha_{i}-\varepsilon_{C i j}\right)$ would be correlated. For example, grandmothers with unobservables that make them less likely to participate in the labor market may be those with higher "family values" and so, with unobservables that increase the probability of taking care of their grandchildren. Alternatively, grandmothers participating in the labor market might be more familiar with the challenges of balancing work and child care responsibilities and thus, they might be more willing to provide care to all their grandchildren. On the other hand, it is not very unrealistic to consider that the unobserved determinants of the participation and care decisions of grandmothers are not correlated with the unobserved determinants of the participation decision of their offspring $\left(\varepsilon_{D j}\right)$. That is, care provided is a given decision for the children. This assumption helps simplify the estimation of the system of equations described in (1) as the model for grandmothers and the model for their offspring can be estimated separately. This assumption, would not hold, however, if there are shocks like changes in the health status of the grandmother that affect both grandmothers' and their offspring's labor participation decisions. To mitigate this possibility, I included controls for grandmother's current health status in the model.

\subsection{Identification}

In order to estimate the model, we assume the following distribution for the unobservables:

$$
\begin{aligned}
\left(\begin{array}{c}
\varepsilon_{G M i} \\
\alpha_{i} \\
\varepsilon_{C i 1} \\
\varepsilon_{C i 2} \\
\varepsilon_{C i 3} \\
\varepsilon_{C i 4} \\
\varepsilon_{D j}
\end{array}\right) \sim N\left[\left(\begin{array}{l}
0 \\
0 \\
0 \\
0 \\
0 \\
0 \\
0
\end{array}\right),\left(\begin{array}{ccccccc}
1 & \sigma_{\alpha, \varepsilon_{G M i}} & 0 & 0 & 0 & 0 & 0 \\
& \sigma_{\alpha}^{2} & 0 & 0 & 0 & 0 & 0 \\
& & 1 & 0 & 0 & 0 & 0 \\
& & & 1 & 0 & 0 & 0 \\
& & & & 1 & 0 & 0 \\
& & & & & 1 & 0 \\
& & &
\end{array}=1,2,3,4\right.\right.
\end{aligned}
$$

Note that $\sigma_{\alpha}^{2}$ denotes the variance of the grandmother's unobserved heterogeneity term capturing her willingness to take care of all her grandchildren while, $\sigma_{\alpha, \varepsilon_{G M i}}$ measures the covariance between the unobserved heterogeneity term and the unobserv- 
ables determining her labor force participation. This covariance coefficient provides information about the importance of the endogeneity problem due to the simultaneity of grandmothers' care and labor participation decisions as well as about the direction of this endogeneity bias. As explained above, the unobservables determining labor participation of the offspring $\left(\varepsilon_{D j}\right)$ are assumed to be independent of those of the grandmother while grandmother's caregiving unobservables are correlated across children only through the unobserved heterogeneity term $\sigma_{\alpha}^{2}$.

In contrast with prior work that aimed to estimate the effect of care provided on grandmothers' labor participation (see, Rupert and Zanella 2018; Frimmel et al. 2017; Backhaus and Barslund 2019), this model aims to identify the reverse effect, that is the effect of participating in the labor market on care provided. For this aim, I use eligibility for early retirement public pensions as an exclusion restriction or external instrument inducing exogenous changes in grandmother's labor participation. The use of eligibility for retirement pensions as instrument in grandmothers' labor participation decisions goes in line with the approach in the recent literature that exploited changes in retirement pensions eligibility to study the effect of grandmother's provided care on mothers' labor participation (see Aparicio Fenoll and Vidal-Fernandez 2015; Aparicio Fenoll 2018; Battistin et al. 2015; Batti et al. 2018).

\subsection{Estimation}

Given previous distributional assumptions, I estimate the model by maximum likelihood. The model for the offspring is a probit decision model. The only econometric problem when estimating this model is due to the fact that the unobservables may be correlated as we have observations of individuals in the same family. To take into account the heteroskedasticity that having data from multiple members of a family could induce, I obtained cluster-robust standard errors.

On the other hand, we estimate the care and participation decisions of grandmothers jointly. As it is described in Sect. 4, for each grandmother we have information about her labor status and about the care provided for grandchildren of at most four of her offspring. Here we exploit this fact to estimate the model including a random effects unobserved heterogeneity term. Consider the case of a grandmother with four offspring, then her contribution to the likelihood would be:

$$
\begin{array}{r}
\operatorname{Pr}\left(\mathrm{PGM}_{i}=a, C_{i 1}=b, C_{i 2}=c, C_{i 3}=d, C_{i 4}=e \mid X\right) \\
a=1,0 ; \quad b=1,0 ; \quad c=1,0 ; \quad d=1,0 ; e=1,0
\end{array}
$$

Defining as $G\left(\alpha_{i}\right)$ the distribution function of the individual random effect we get:

$$
\begin{aligned}
\operatorname{Pr}\left(\mathrm{PGM}_{i}\right. & \left.=a, C_{i 1}=b, C_{i 2}=c, C_{i 3}=d, C_{i 4}=e \mid X\right) \\
& =\int_{-\infty}^{\infty} \operatorname{Pr}\left(\mathrm{PGM}_{i}=a, C_{i 1}=b, C_{i 2}=c, C_{i 3}=d, C_{i 4}=e \mid X, \alpha_{i}\right) d G\left(\alpha_{i}\right)
\end{aligned}
$$




$$
\begin{aligned}
= & \int_{-\infty}^{\infty} \operatorname{Pr}\left(\mathrm{PGM}_{i}=a, C_{i 1}=b, C_{i 2}=c, C_{i 3}=d, C_{i 4}=e \mid X, \alpha_{i}, \mathrm{PGM}_{i}=a\right) \\
& \times \operatorname{Pr}\left(\mathrm{PGM}_{i}=a \mid X, \alpha_{i}\right) d G\left(\alpha_{i}\right) \\
= & \int_{-\infty}^{\infty} \operatorname{Pr}\left(C_{i 1}=b \mid X, \alpha_{i}, \mathrm{PGM}_{i}=a\right) \operatorname{Pr}\left(C_{i 2}=c \mid X, \alpha_{i}, \mathrm{PGM}_{i}=a\right) \\
& \times \operatorname{Pr}\left(C_{i 3}=d \mid X, \alpha_{i}, \mathrm{PGM}_{i}=a\right) \operatorname{Pr}\left(C_{i 4}=e \mid X, \alpha_{i}, \mathrm{PGM}_{i}=a\right) \\
& \times \operatorname{Pr}\left(\mathrm{PGM}_{i}=a \mid X, \alpha_{i}\right) d G\left(\alpha_{i}\right)
\end{aligned}
$$

The last step comes from the fact that we assume that, the caregiving decisions are only correlated through the grandmother's unobserved heterogeneity term $\left(\alpha_{i}\right)$. In the same way, we obtain the contribution to the likelihood of grandmothers with information about three, two or one offspring. I maximize the log-likelihood function using Gauss Hermite integral procedures evaluated in 26 points.

\section{Results}

\subsection{Labor participation of the offspring}

In this section, I present estimates for the labor participation decision of the grandmothers' offspring. I estimate separate models for sons and daughters. Table 7 presents the estimated coefficients for a probit model of the participation decision of daughters. The set of explanatory variables include age, number of children, level of education, marital status, a set of institutional variables representing characteristics of the child care system in her country of residence, as discussed in the previous section, and interactions between country dummies and a dummy indicating whether care was provided by the grandmother. These variables are constructed with the information presented in Tables 2 and 3. Country controls are also included in the regressions directly to capture any remaining country unobserved differences that could affect female labor participation.

Age and education variables both have a positive effect on the labor participation of daughters, while the higher the number of children the lower the daughters' probability of participating in the labor market. Concerning institutional differences, I found a negative but small and no statistically significant effect of the generosity of parental leave policies on the daughters' probability of participating in the labor market, for daughters of children under preschool age. This result goes in line with the literature that has found that, while short and medium-length parental leaves benefit female employment, prolonged parental leaves could have a negative effect on mothers' labor participation (see e.g., Ruhm 1998). In contrast, the probability of participating in the labor market of daughters with young children does appear to be lower in countries with higher child care fees. Similar results were found for Germany, Sweden, Norway and Italy in studies that ignored the possibility of informal care providers (see e.g., 
Table 7 Probit estimates of the labor participation decision of the daughter

\begin{tabular}{|c|c|c|c|}
\hline Variable & Coef. & Variable & Coef. \\
\hline Age & $\begin{array}{l}0.033 * * * \\
(0.010)\end{array}$ & Germany & $\begin{array}{l}-0.73 \\
(0.47)\end{array}$ \\
\hline Number of children & $\begin{array}{l}-0.18 * * * \\
(0.047)\end{array}$ & Netherlands & $\begin{array}{l}-2.44 * * \\
(1.04)\end{array}$ \\
\hline High education level & $\begin{array}{l}0.81 * * * \\
(0.13)\end{array}$ & Spain & $\begin{array}{l}-4.49 * * \\
(1.75)\end{array}$ \\
\hline Medium education level & $\begin{array}{l}0.39 * * * \\
(0.10)\end{array}$ & Italy & $\begin{array}{l}0.24 \\
(0.31)\end{array}$ \\
\hline Married & $\begin{array}{l}0.0088 \\
(0.11)\end{array}$ & France & $\begin{array}{l}-4.01 * * * \\
(1.43)\end{array}$ \\
\hline Child younger preschool age & & Greece & $\begin{array}{l}-0.87 * * \\
(0.40)\end{array}$ \\
\hline Parental leave & $\begin{array}{l}-0.00046 \\
(0.0035)\end{array}$ & Belgium & $\begin{array}{l}-3.05 * * \\
(1.21)\end{array}$ \\
\hline Fees child care & $\begin{array}{l}-0.16 * * \\
(0.062)\end{array}$ & Care received & \\
\hline Child preschool_compulsory age & & Austria & $\begin{array}{l}0.20 \\
(0.31)\end{array}$ \\
\hline Austria & $\begin{array}{l}-0.83 \\
(0.65)\end{array}$ & Germany & $\begin{array}{l}0.38 \\
(0.23)\end{array}$ \\
\hline Germany & $\begin{array}{l}-0.85 * \\
(0.49)\end{array}$ & Sweden & $\begin{array}{l}-0.051 \\
(0.21)\end{array}$ \\
\hline Netherlands & $\begin{array}{l}-2.84 * * * \\
(1.071)\end{array}$ & Netherlands & $\begin{array}{l}0.87 * * * \\
(0.23)\end{array}$ \\
\hline Spain & $\begin{array}{l}-4.93 * * * \\
(1.75)\end{array}$ & Spain & $\begin{array}{l}0.39 \\
(0.30)\end{array}$ \\
\hline Italy & $\begin{array}{l}0.62 * \\
(0.32)\end{array}$ & Italy & $\begin{array}{l}0.28 \\
(0.27)\end{array}$ \\
\hline France & $\begin{array}{l}-4.35 * * * \\
(1.43)\end{array}$ & France & $\begin{array}{l}0.38 * \\
(0.22)\end{array}$ \\
\hline Greece & $\begin{array}{l}-0.57 \\
(0.47)\end{array}$ & Denmark & $\begin{array}{l}0.095 \\
(0.38)\end{array}$ \\
\hline Belgium & $\begin{array}{l}-3.07 * * \\
(1.21)\end{array}$ & Greece & $\begin{array}{l}0.69 * * \\
(0.34)\end{array}$ \\
\hline Child older compulsory age & & Belgium & $\begin{array}{l}0.49 * * \\
(0.23)\end{array}$ \\
\hline Austria & $\begin{array}{l}-3.03 \\
(0.55)\end{array}$ & Constant & $\begin{array}{l}-0.0026 \\
(0.41)\end{array}$ \\
\hline
\end{tabular}

(i) Country controls are also included, N. obs: 1452 (ii) Source: SHARE, (iii) Cluster-robust standard errors in parenthesis

$* * *$ Significance at a $99 \%, * *$ at $95 \%$ and $*$ at $90 \%$ level 
Wrohlich 2004, 2011; Kornstad and Thoresen 2007; Gustafsson and Stafford 1992; del Boca and Vuri 2005).

In comparison with the Northern European countries (Denmark and Sweden), mothers of children in preschool age living in The Netherlands, Spain, France, and Belgium have a lower probability of participating in the labor market. It should be pointed out that all these countries except Spain have limited opening hours of their public preschool centers, as it is shown in Table 3. These observed differences in mothers' labor participation persist for those whose children are at the compulsory education age or older. In addition, daughters' probability of participating in the labor market is lower for Greek mothers in this case.

The grandchild care provided by grandmothers has a positive and significant effect on their daughters' probability of labor participation but only for those living in The Netherlands, Greece, Belgium, and France. It should be stressed out, however, that these estimates correspond to the effect of care provided by working-age grandmothers (aged 50-65) only. It could be that for some countries care provided by older non-working age grandmothers helps daughters' labor participation. In fact, Aparicio Fenoll (2018) finds that grandmothers' retirement induced by reaching full retirement ages does have a positive effect on daughters' labor supply for countries with low family benefits, including Greece, Italy, The Netherlands, and Spain.

Table 8 shows the estimated coefficients for the labor participation decision of sons. In this case, there were no statistically significant effects of any of the institutional variables. Therefore, I present a simplified model that excluded these variables in the table. For the case of sons, grandchild care provided by grandmothers does not have a significant effect on their probability of participating in the labor market and the only significant country effect found was for the case of Germany. Living in Germany appears to significantly reduce the probability of sons' participating in the labor market. This latter result may be indicating a particularly bad economic situation for this country in the year of the survey. Finally, being married had a positive and significant effect on the sons' labor participation.

\subsection{Care and participation decisions of the grandmother}

\subsubsection{Estimates without taking endogeneity into account}

In this section, I first present estimates using a simple probit model to study the determinants of the grandmother's decision of providing care to their grandchildren. Note that this estimation approach does not correct for the possible endogeneity of grandmothers' decision to participate in the labor market. The next section shows estimates for the determinants of grandmothers' provided care and labor participation decisions simultaneously. Thus, the next section estimates take endogeneity of labor participation into account. The explanatory variables in this simple probit model for provided grandchild care include age dummies, grandmother's participation in the labor market, number of grandchildren, marital status of the child, self-reported health, a dummy for the child living further than $25 \mathrm{~km}$, and a dummy for the child being a daughter. Institutional variables capturing differences in child care systems across 
Table 8 Probit estimates of the labor participation decision of the son

\begin{tabular}{ll}
\hline Variable & Coef. \\
\hline Age & -0.013 \\
& $(0.020)$ \\
Number of children & 0.033 \\
& $(0.097)$ \\
High education level & $0.82 * * *$ \\
& $(0.26)$ \\
Medium education level & 0.28 \\
& $(0.17)$ \\
Married & $0.56 * * *$ \\
& $(0.17)$ \\
Age youngest child & 0.015 \\
Child care received & $(0.027)$ \\
Germany & 0.22 \\
Constant & $(0.17)$ \\
& $-0.64 * * *$ \\
& $(0.21)$ \\
& 1.40 \\
& $(0.63)$
\end{tabular}

(i) N. obs: 1093 (ii) Source: SHARE, (iii) Cluster robust standard errors in parenthesis

$* * *$ Significance at a $99 \%, * *$ at $95 \%$ and $*$ at $90 \%$ level

countries are also included in the same way as they were introduced in the daughters' labor participation model presented above. That is, parental leave generosity measures and fees in child care are introduced as an interaction term depending on the youngest grandchild being younger than preschool age. The model also includes differential effects depending on the youngest grandchild being in preschool age or in compulsory school age or older, by country. Finally, country fixed effects are also included to capture any remaining unobserved differences across countries.

As it is shown in Table 9, those grandmothers who participate in the labor market have a lower probability of taking care of their grandchildren. Having more grandchildren also negatively correlates with the probability of caregiving. Surprisingly, not having good health does not seem to have a very strong effect on grandchild care provided. If the child lives further than $25 \mathrm{~km}$, the probability of the grandmother providing grandchild care is lower. An interesting result is that grandchild care seems to be provided with a higher probability from mothers to daughters than from mothers to sons.

With respect to institutional variables, grandmothers of young children in countries with higher child care fees provide care with a higher probability. This suggests that the grandmother's care might be used as a substitute when child care facilities are too expensive. Grandchild care is provided with a higher probability in Italy and Belgium for grandchildren in preschool age. In addition, Italian and Greek grandmothers 
Table 9 Random effect probit estimates of the caregiving decision

\begin{tabular}{|c|c|c|c|}
\hline Variable & Coef. & Variable & Coef. \\
\hline Age $50-55$ & $\begin{array}{l}0.10 \\
(0.10)\end{array}$ & Spain & $\begin{array}{l}0.54 * * \\
(0.26)\end{array}$ \\
\hline Age $56-60$ & $\begin{array}{l}-0.056 \\
(0.089)\end{array}$ & Italy & $\begin{array}{l}1.27 * * * \\
(0.27)\end{array}$ \\
\hline Labor participation & $\begin{array}{l}-0.28 * * * \\
(0.096)\end{array}$ & France & $\begin{array}{l}0.30 \\
(0.19)\end{array}$ \\
\hline Number of grandchildren & $\begin{array}{l}-0.15 * * * \\
(0.043)\end{array}$ & Greece & $\begin{array}{l}0.63 * \\
(0.35)\end{array}$ \\
\hline Married child & $\begin{array}{l}0.023 \\
(0.093)\end{array}$ & Belgium & $\begin{array}{l}0.58 * * * \\
(0.19)\end{array}$ \\
\hline Less than good health & $\begin{array}{l}-0.13 * \\
(0.082)\end{array}$ & Older compulsory age & \\
\hline Living further than $25 \mathrm{~km}$ & $\begin{array}{l}-1.53 * * * \\
(0.12)\end{array}$ & Austria & $\begin{array}{l}0.32 \\
(0.22)\end{array}$ \\
\hline Daughter & $\begin{array}{l}0.52 * * * \\
(0.076)\end{array}$ & Germany & $\begin{array}{l}0.31 \\
(0.20)\end{array}$ \\
\hline Younger preschool age & & Netherlands & $\begin{array}{l}-0.23 \\
(0.21)\end{array}$ \\
\hline Parental leave & $\begin{array}{l}-0.00066 \\
(0.0012)\end{array}$ & Spain & $\begin{array}{l}0.010 \\
(0.28)\end{array}$ \\
\hline Fees child care & $\begin{array}{l}0.018 * * * \\
(0.0058)\end{array}$ & Italy & $\begin{array}{l}1.16 * * * \\
(0.25)\end{array}$ \\
\hline Italy & $\begin{array}{l}0.64 * * \\
(0.25)\end{array}$ & France & $\begin{array}{l}0.26 \\
(0.21)\end{array}$ \\
\hline Preschool-compulsory age & & Greece & $\begin{array}{l}0.94 * * * \\
(0.26)\end{array}$ \\
\hline Austria & $\begin{array}{l}0.64 * \\
(0.38)\end{array}$ & Belgium & $\begin{array}{l}0.21 \\
(0.19)\end{array}$ \\
\hline Germany & $\begin{array}{l}0.36 \\
(0.24)\end{array}$ & Constant & $\begin{array}{l}-0.19 \\
(0.17)\end{array}$ \\
\hline Netherlands & $\begin{array}{l}0.20 \\
(0.27)\end{array}$ & $\sigma_{\alpha}$ & $\begin{array}{l}0.79 * * * \\
(0.096)\end{array}$ \\
\hline
\end{tabular}

(i) Country controls also included. N. obs: 2545 (ii) Source: SHARE, (iii) Cluster robust standard errors in parenthesis

$* * *$ Significance at a $99 \%, * *$ at $95 \%$ and $*$ at $90 \%$ level

provide care to their grandchildren at the compulsory education age or older with a higher probability. If we compare these results with the results for the daughters' labor participation decisions, presented in Table 7, I find that for Spain and Belgium there is a significant negative effect on labor participation for mothers of children in preschool age and a corresponding significant higher probability of grandmothers providing care. 
In contrast, for France and The Netherlands, I found significant negative effects on the labor participation of mothers of preschool age children but not a corresponding significant effect on working-age grandmothers' provided care. Considering grandchildren of compulsory school age or older, we observe that for those countries with significant negative effects on the labor participation of mothers whose youngest child is in this age range (i.e., The Netherlands, Greece and Belgium), with the exception of Greece, we do not observe significant effects on grandmothers' provided care. This suggests that the adjustment to the necessity of child care of compulsory school-age children in these countries is performed to a greater extent through a reduction in the daughters' labor supply and to a lesser extent through an increase in working-age grandmothers' grandchild care. Finally, the variance of the grandmother's random effect is significant indicating the importance of controlling for unobserved heterogeneity.

\subsubsection{Joint estimates of care and labor participation decisions}

The estimates presented in the previous section do not take into account the potential endogeneity of labor participation decisions and so, the estimated coefficient of the effect of labor participation in grandchild care decisions cannot be interpreted as causal. In this section, I present estimates that correct for the potential endogeneity of labor participation decisions by maximizing the joint likelihood of grandchild care and labor participation decisions as described in (2).

Table 10 shows the estimated coefficients for the labor participation decision of the grandmother. Age and education have the expected effect, labor participation declines with grandmother's age and increases with grandmother's education level. Married grandmothers participate in the labor market with a lower probability. Health-related variables have also the expected coefficient's sign, the healthier the grandmother the higher the probability of participating in the labor market. Grandmothers with partners still working participate in the labor market with a higher probability. However, the higher the level of education of the partner the lower the probability of the grandmother participating in the labor market. Importantly, being above the early retirement age, the exclusion restriction has a negative and significant effect on the probability of grandmothers' labor participation.

Table 11 shows the estimated coefficients for the caregiving decisions. Once I control for the potential endogeneity of grandmothers' labor participation, I find a bigger estimated effect for this variable. Participating in the labor market has a significant and negative effect on the probability of grandmothers' providing care to their grandchildren. Moreover, we now find that having not good health has a negative and significant effect.

As expected younger grandmothers provide care with a higher probability. As it was found in previous estimates without controlling for endogeneity, living further than 25 $\mathrm{km}$ decreases the probability of grandmothers providing grandchild care while if the child is a daughter it increases it. Grandmothers of children under preschool age who live in countries with higher child care fees provide care with a higher probability but the effect is smaller than in the estimates presented in the previous section. Finally, grandmothers of preschool children living in Italy and Greece continue providing care with a higher probability. This is not the case anymore for Spanish grandmothers of 
Table 10 Maximum likelihood estimates. Labor participation decision of the grandmother

\begin{tabular}{|c|c|c|c|}
\hline Variable & Coef. & Variable & Coef. \\
\hline Age $50-55$ & $\begin{array}{l}1.17 * * * \\
(0.20)\end{array}$ & Over early retirement age & $\begin{array}{l}-0.36 * * \\
(0.16)\end{array}$ \\
\hline Age $56-60$ & $\begin{array}{l}0.75 * * * \\
(0.17)\end{array}$ & Other household income & $\begin{array}{l}-0.96 \\
(1.85)\end{array}$ \\
\hline High education level & $\begin{array}{l}0.51 * * * \\
(0.11)\end{array}$ & Austria & $\begin{array}{l}-1.31 * * * \\
(0.20)\end{array}$ \\
\hline Medium education level & $\begin{array}{l}0.14 \\
(0.089)\end{array}$ & Germany & $\begin{array}{l}-0.84 * * * \\
(0.14)\end{array}$ \\
\hline Married & $\begin{array}{l}-0.19 * * \\
(0.095)\end{array}$ & Netherlands & $\begin{array}{l}-1.02 * * * \\
(0.12)\end{array}$ \\
\hline Less than good health & $\begin{array}{l}-0.44 * * * \\
(0.095)\end{array}$ & Spain & $\begin{array}{l}-1.33 * * * \\
(0.19)\end{array}$ \\
\hline $2+$ chronic & $\begin{array}{l}-0.18 * * \\
(0.083)\end{array}$ & Italy & $\begin{array}{l}-1.65 * * * \\
(0.22)\end{array}$ \\
\hline Limited mobility & $\begin{array}{l}-0.10 \\
(0.086)\end{array}$ & France & $\begin{array}{l}-0.79 * * * \\
(0.13)\end{array}$ \\
\hline Maximum grip & $\begin{array}{l}0.34 \\
(0.61)\end{array}$ & Greece & $\begin{array}{l}-1.83 * * * \\
(0.24)\end{array}$ \\
\hline Partner L. participation & $\begin{array}{l}0.29 * * * \\
(0.11)\end{array}$ & Belgium & $\begin{array}{l}-1.22 * * * \\
(0.12)\end{array}$ \\
\hline High educated partner & $\begin{array}{l}-0.26 * * \\
(0.13)\end{array}$ & Constant & $\begin{array}{l}-0.54 * * \\
(0.27)\end{array}$ \\
\hline Medium educated partner & $\begin{array}{l}-0.22 * \\
(0.12)\end{array}$ & & \\
\hline
\end{tabular}

preschool children as the effect is not statistically significative now that we accounted for endogeneity of grandmothers' labor participation. Similarly, the estimated effect for Belgium is only now marginally significant. Italian and Greek grandmothers of compulsory school-age children or older continue to appear to provide care with a higher probability.

The estimates also show a significant variance of the grandmother's unobserved heterogeneity term. This indicates the importance of controlling for unobserved heterogeneity in grandmothers' grandchild care decisions. The estimated correlation between the unobserved heterogeneity term and the unobservables in the labor participation decision turned out to be negative and significant indicating that those working-age grandmothers with a higher probability of participating in the labor market are also those with unobservables that urge them to take care of their grandchildren. This result suggests that grandmothers participating in the labor market may be more familiar with the challenges of balancing work and care responsibilities and might be more willing to provide grandchild care. 
Table 11 Maximum likelihood estimates. Caregiving decision

\begin{tabular}{|c|c|c|c|}
\hline Variable & Coef. & Variable & Coef. \\
\hline Age $50-55$ & $\begin{array}{l}0.45 * * * \\
(0.14)\end{array}$ & Italy & $\begin{array}{l}1.03 * * * \\
(0.30)\end{array}$ \\
\hline Age $56-60$ & $\begin{array}{l}0.16 \\
(0.11)\end{array}$ & France & $\begin{array}{l}0.19 \\
(0.20)\end{array}$ \\
\hline Labor participation & $\begin{array}{l}-1.14 * * * \\
(0.25)\end{array}$ & Greece & $\begin{array}{l}0.33 \\
(0.35)\end{array}$ \\
\hline Number of grandchildren & $\begin{array}{l}-0.14 * * * \\
(0.045)\end{array}$ & Belgium & $\begin{array}{l}0.38 * \\
(0.20)\end{array}$ \\
\hline Married child & $(0.095)-0.0060$ & Older compulsory age & \\
\hline Less than good health & $\begin{array}{l}-0.26 * * * \\
(0.092)\end{array}$ & Austria & $\begin{array}{l}0.10 \\
(0.24)\end{array}$ \\
\hline Living further than $25 \mathrm{~km}$ & $\begin{array}{l}-1.52 * * * \\
(0.12)\end{array}$ & Germany & $\begin{array}{l}0.19 \\
(0.23)\end{array}$ \\
\hline Daughter & $\begin{array}{l}0.52 * * * \\
(0.079)\end{array}$ & Netherlands & $\begin{array}{l}-0.42 * \\
(0.22)\end{array}$ \\
\hline Younger preschool age & & Spain & $\begin{array}{l}-0.23 \\
(0.30)\end{array}$ \\
\hline Parental leave & $\begin{array}{l}0.00052 \\
(0.0013)\end{array}$ & Italy & $\begin{array}{l}0.92 * * * \\
(0.26)\end{array}$ \\
\hline Fees child care & $\begin{array}{l}0.0077 * * * \\
(0.0066)\end{array}$ & France & $\begin{array}{l}0.14 \\
(0.22)\end{array}$ \\
\hline Italy & $\begin{array}{l}0.29 \\
(0.29)\end{array}$ & Greece & $\begin{array}{l}0.67 * * * \\
(0.27)\end{array}$ \\
\hline Preschool_compulsory age & & Belgium & $\begin{array}{l}0.00098 \\
(0.20)\end{array}$ \\
\hline Austria & $\begin{array}{l}0.44 \\
(0.33)\end{array}$ & Constant & $\begin{array}{l}0.088 \\
(0.19)\end{array}$ \\
\hline Germany & $\begin{array}{l}0.23 \\
(0.26)\end{array}$ & $\sigma_{\alpha \varepsilon}$ & $\begin{array}{l}-0.57 * * * \\
(0.15)\end{array}$ \\
\hline Netherlands & $\begin{array}{l}0.022 \\
(0.30)\end{array}$ & $\sigma_{\alpha}$ & $\begin{array}{l}0.77 * * * \\
(0.19)\end{array}$ \\
\hline Spain & $\begin{array}{l}0.32 \\
(0.29)\end{array}$ & & \\
\hline
\end{tabular}

(i) Country controls also included, N. obs: 2545 (ii) Source: SHARE, (iii) Log-likelihood: -2151.786423. Standard errors in parenthesis

$* * *$ Significance at a $99 \%, * *$ at $95 \%$ and $*$ at $90 \%$ level

\section{Conclusions}

The dramatic rise in women's labor force participation rates during the past four decades has significantly increased the demand for non-maternal child care. One source 
for this care is grandmothers. Indeed, grandmothers have become one of the primary providers of child care for children in Europe and the provision of this informal care is a significant intergenerational time transfer. In this paper, I studied to what extent grandchild care is provided by grandmothers and how this task is combined with their paid work. In addition, I studied whether this care provided by grandmothers is encouraging the labor participation of their offspring.

In contrast with prior work that has studied the effect of grandmothers' care on their labor participation (see, Rupert and Zanella 2018; Frimmel et al. 2017; Backhaus and Barslund 2019), I focus the analysis on working-age grandmothers (aged 50-65) and study the reverse effect, that is the effect of grandmothers' labor participation on provided grandchild care. The empirical approach takes into account the simultaneity of labor market decisions and caregiving activities while controlling for grandmother's unobserved heterogeneity on their willingness to provide care to their grandchildren. In line with recent work that used eligibility ages for retirement as external instruments for grandmothers' labor participation (see Aparicio Fenoll and Vidal-Fernandez 2015; Aparicio Fenoll 2018; Battistin et al. 2015; Batti et al. 2018), I use the information on eligibility for early retirement as an exclusion restriction to aid identification of the empirical model.

I find a negative and significant effect of participating in the labor market on the probability of taking care of the grandchildren at least weekly. From the point of view of policymakers, this is an important finding because recent tendencies to try to prolong grandparents' working life might change the care provided to grandchildren and affect the labor supply of young mothers by changing the set of child care options that are available. Moreover, the quality of child care is an important determinant of a child's development (see Peisner-Feinberg et al. 2001). Thus, if the care provided by grandmothers is not substituted by formal care of equal or better quality, the reduction in grandmothers' care may also have implications on the child's development.

I also find that the grandmothers of young children in countries with higher child care fees provide care with a higher probability. This suggests that the grandmothers' care might be used as a substitute when child care facilities are too expensive. In addition, I find that, for the case of France, The Netherlands, and Spain, when accounting for endogeneity of grandmothers' labor participation, grandmothers of preschool age children are not providing care with a higher probability. This is despite an estimated significant negative effect on the labor participation of preschool mothers in these countries. A similar result is observed for the case of compulsory school-age children in the Netherlands and Belgium. This suggests that care needs for children in these ages and in these countries are being solved to a greater extent through reductions in the daughters' labor supply than with increases in grandmothers' care. Finally, I find a positive effect of the offspring being a daughter on the probability of providing grandchild care indicating that this kind of time transfer is most frequently provided from mothers to daughters.

Concerning the offspring's labor participation, I find evidence that care received has a positive and significant effect on the labor participation of mothers but only for those living in The Netherlands or in Greece. However, I have to acknowledge several limitations of this analysis and results. Firstly, my analysis focuses only on working-age grandmothers. It is possible that for some countries care provided by older 
non-working age grandmothers benefits daughters' labor participation. Secondly, due to the computational intensity of the estimated models and the need for exclusion restrictions, I am not able to study how grandmothers' are combining grandchild care with work full-time or part-time, separately. I am also not able to study care provided on a weekly or a daily basis, separately. Finally, my analysis only uses data of the first wave of SHARE while more waves of data are now available. I encourage researchers to replicate these results in more recent waves and to further the analysis along these lines.

Acknowledgements This paper uses data from SHARE Wave 1 (https://doi.org/10.6103/SHARE.w1.700), see Börsch-Supan et al. (2013) for methodological details. The SHARE data collection has been funded by the European Commission through FP5 (QLK6-CT-2001-00360), FP6 (SHARE-I3: RII-CT-2006-062193, COMPARE: CIT5-CT-2005-028857, SHARELIFE: CIT4-CT-2006-028812), FP7 (SHARE-PREP: GA N211909, SHARE-LEAP: GA N227822, SHARE M4: GA N261982) and Horizon 2020 (SHARE-DEV3: GA N676536, SERISS: GA N654221) and by DG Employment, Social Affairs \& Inclusion. Additional funding from the German Ministry of Education and Research, the Max Planck Society for the Advancement of Science, the USA. National Institute on Aging and from various national funding sources is gratefully acknowledged (see www.share-project.org).

\section{Compliance with ethical standards}

Conflict of interest The author declares that she has no conflict of interest.

Open Access This article is licensed under a Creative Commons Attribution 4.0 International License, which permits use, sharing, adaptation, distribution and reproduction in any medium or format, as long as you give appropriate credit to the original author(s) and the source, provide a link to the Creative Commons licence, and indicate if changes were made. The images or other third party material in this article are included in the article's Creative Commons licence, unless indicated otherwise in a credit line to the material. If material is not included in the article's Creative Commons licence and your intended use is not permitted by statutory regulation or exceeds the permitted use, you will need to obtain permission directly from the copyright holder. To view a copy of this licence, visit http://creativecommons.org/licenses/by/4.0/.

\section{References}

Ahn N, Mira P (2002) A note on the changing relationship between fertility and female employment rates in developed countries. J Popul Econ 15:667-682

Aparicio Fenoll A (2018) The uneven impact of women's retirement on their daughters' employment, CIRCLE Working Paper 2, June

Aparicio Fenoll A, Vidal-Fernandez M (2015) Working women and fertility: the role of grandmothers' labor force participation. CESifo Econ Stud 61(1):123-147

Backhaus A, Barslund M (2019) The effect of grandchildren on grandparental labor supply: evidence from Europe, SHARE Working Paper Series 34-2019

Battistin E, De Nadai M, Padula M (2015) Roadblocks on the road to grandma's house: fertility consequences of delayed retirement, Queen Mary, University of London Working Paper No. 748

Blau D, Robins P (1988) Child care costs and family labor supply. Rev Econ Stat 70:374-381

Bratti M, Frattini T, Scervini F (2018) Grandparental availability for child care and maternal labor force participation: pension reform evidence from Italy. J Popul Econ 31:1239-1277. https://doi.org/10. 1007/s00148-017-0683-7

Börsch-Supan A, Brandt M, Hunkler C, Kneip T, Korbmacher J, Malter F, Schaan B, Stuck S, Zuber S (2013) Data resource profile: the survey of health, ageing and retirement in Europe (SHARE). Int J Epidemiol. https://doi.org/10.1093/ije/dyt088

Börsch-Supan A (2018) Survey of Health Ageing and Retirement in Europe (SHARE) Wave 1. Release version: 6.1.0. SHARE-ERIC 
Cardia E, Ng S (2003) Intergenerational time transfers and childcare. Rev Econ Dyn 6:431-454

Connelly R (1992) The effect of child care costs on married women's labor force participation. Rev Econ Stat 74(1):83-90

del Boca D, Vuri D (2005) Labor supply and child care costs: the effect of rationing, labor and demography, 0510016. University Library of Munich, Munich

Dimova R, Wolff F (2011) Do downward private transfers enhance maternal labor supply? Evidence from around Europe. J Popul Econ 24(3):911-933

Frimmel W, Halla M, Schmidpeter B, Winter-Ebmer R (2017) Grandmothers' labor supply, Johannes Kepler University of Linz, Department of Economics Working paper 1720, December

Garcia-Moran E, Kuehn Z (2017) With strings attached: grandparent-provided child care and female labor market outcomes. Rev Econ Dyn 23:80-98

Gustafsson S, Stafford F (1992) Child care subsidies and labor supply in Sweden. J Hum Resour 27(1):204230

Heckman J (1974) The effect of child care programs on women work effort. J Polit Econ 82(2):136-63

Ho C (2015) Grandchild care, intergenerational transfers, and grandparents' labor supply. Rev Econ Househ 13(2):359-384

Kimmel J (1998) Child care costs as a barrier to employment for single and married mothers. Rev Econ Stat 80:287-299

Kornstad T, Thoresen TO (2007) A discrete choice model for labor supply and child care. J Popul Econ 20(4):781-803

Lei X (2008) Grandchild care, financial transfers and grandma's labor market decisions, manuscript

Lumsdaine R, Vermeer S (2015) Retirement timing of women and the role of care responsibilities for grandchildren. Demography 52(2):433-454

Natali D (2004) The Pension System Observatoire Social Européen Research Project: LA METHODE OUVERTE DE COORDINATION (MOC) EN MATIERE DES PENSIONS ET DE L'INTEGRATION EUROPEENNE, Service Public Fédéral Sécurité Sociale

OECD (2001) Starting strong. Early childhood education and care

OECD (2003) Economic survey of Austria. https://www.oecd-ilibrary.org/economics/oecd-economicsurveys-austria-2003_eco_surveys-aut-2003-en Accessed Feb 2020

OECD (2004) Social expenditure database. https://www.oecd.org/social/expenditure.htm. Accessed Feb 2020

OECD (2005) Vieillissement et politiques de l'emploi. Ageing and Employment Policies, France. https:// www.oecd-ilibrary.org/employment/ageing-and-employment-policies-vieillissement-et-politiquesde-1-emploi-france-2005_9789264008878-en. Accessed Feb 2020

OECD (2007) Benefits and wages: OECD indicators. http://www.oecd.org/social/soc/ benefitsandwages2007.htm. Accessed Feb 2020

OECD (2020) Part-time employment rate (indicator). https://data.oecd.org/emp/part-time-employmentrate.htm. Accessed Feb 2020

Peisner-Feinberg ES, Burchinal MR, Clifford RM, Culkin ML, Howes C, Kagan SL, Yazejian N (2001) The relation of preschool child care quality to children's cognitive and social developmental trajectories through second grade. Child Dev 72(5):1534-1553

Plantenga J, Siegel M (2004) European child care strategies, position paper for the conference child care in a changing world

Posadas J, Vidal-Fernandez M (2013) Grandparents' childcare and female labor force participation. IZA J Labor Policy 2:14

Preesman L (2006) Dutch to abolish civil service retirement age. IPE International Publishers Ltd, Amsterdam

Reinkowski J (2013) Does grandchild care conflict with grandparents' employment. Technical Report, Ifo Institute, Munich

Ribar D (1992) Child care and the labor supply of married women: reduced form evidence. J Hum Resour 27(1):134-165

Ruhm C (1998) The economic consequences of parental leave mandates: lessons from Europe. Q J Econ 113(1):285-317

Rupert P, Zanella G (2018) Grandchildren and their grandparents' labor supply. J Public Econ 159:89-103 Sundén A (2004) The future of retirement in Sweden, Pension Research Council Working Paper 2004-16

The Bartelsmann Foundation (2003) International Reform Monitor, Country info. http://www. reformmonitor.org/index.php3?mode=status. Accessed Jan 2011 
Wrohlich K (2004) Child care costs and mother's labor supply: an empirical analysis for Germany, DIW Discussion Papers, 412

Wrohlich K (2011) Labor supply and child care choices in a rationed child care market, DIW Discussion Papers, 1169

Publisher's Note Springer Nature remains neutral with regard to jurisdictional claims in published maps and institutional affiliations. 